\title{
A Look into the Cockpit of the Fly: Visual Orientation, Algorithms, and Identified Neurons
}

\author{
Martin Egelhaaf and Alexander Borst \\ Max-Planck-Institut für biologische Kybernetik, 72076 Tübingen, Germany
}

The top-down approach to understanding brain function seeks to account for the behavior of an animal in terms of biophysical properties of nerve cells and synaptic interactions via a series of progressively reductive levels of explanation. Using the fly as a model system, this approach was pioneered by Werner Reichardt and his colleagues in the late 1950s. Quantitative input-output analyses led them to formal algorithms that related the input of the fly's eye to the orientation behavior of the animal. But it has been possible only recently to track down the implementation of part of these algorithms to the computations performed by individual neurons and small neuronal ensembles. Thus, the visually guided flight maneuvers of the fly have turned out to be one of the few cases in which it has been feasible to reach an understanding of the mechanisms underlying a complex behavioral performance at successively reductive levels of analysis. These recent findings illuminate some of the fundamental questions that are being debated in computational neuroscience (Marr and Poggio, 1977; Sejnowski et al., 1988; Churchland and Sejnowski, 1992). (1) Are some brain functions emergent properties present only at the systems level? (2) Does an understanding of brain function at the systems level help in understanding function at the cellular and subcellular level? (3) Can different levels of organization be understood independently of each other?

In this review we concentrate on two basic computational tasks that have to be solved by the fly, as well as by many other moving animals: (1) stabilization of an intended course against disturbances and (2) intended deviations from a straight course in order to orient toward salient objects. Performing these tasks depends on the extraction of motion information from the changing distribution of light intensity received by the eyes.

\section{A Top-Down Approach to Visual Orientation}

The problem of how the fly accomplishes the computational tasks of course stabilization and object detection was initially approached by behavioral experiments. The performance of the animal under free-flight conditions would seem to be a natural

\footnotetext{
This article is dedicated to the memory of Werner Reichardt, a pioneer of computational neuroscience. We thank K. G. Götz, A.-K. Warzecha, and J. M. Zanker for helpful discussions.

Correspondence should be addressed to Martin Egelhaaf, Max-Planck-Institut für biologische Kybernetik, Spemannstrasse 38, 72076 Tübingen, Germany. Copyright $(\mathcal{C} 1993$ Society for Neuroscience $0270-6474 / 93 / 134563-12 \$ 05.00 / 0$
}

starting point for a behavioral analysis (Fig. $1 A$ ) (e.g., Land and Collett, 1974; Wehrhahn et al., 1982; Wagner, 1986a,b; Zeil, 1986). Free-flight behavior, however, is usually too complex for a sufficiently detailed visual input-motor output analysis intended to elucidate the underlying computational processes. Such detailed analyses became possible with the development of a flight simulator (Fig. 1B) (Fermi and Reichardt, 1963; Götz, 1964). This device measures the torque exerted by the fly in tethered flight, while the visual environment can be manipulated in an arbitrary way. Under these restrictive conditions, the fly still exhibits its basic orientation behavior, thus allowing determination of quantitative stimulus-response relationships for the analysis of compensatory course stabilization and orientation behavior.

The behavioral analysis led to models of the underlying mechanisms. Initially, phenomenological theories were formulated that formally relate visual input parameters, such as the velocity or spatial position of an object in the visual field of the fly, to motor output parameters, such as the fly's turning velocity (Fig. 1E) (Poggio and Reichardt, 1976; Reichardt and Poggio, 1976). Subsequently, models were formulated in terms of informationprocessing circuits that specify explicitly the computations being carried out (Fig. 1F) (Reichardt ct al., 1983, 1989; Egelhaaf, 1985a,c; Borst, 1990).

These models, in turn, led to predictions with respect to their underlying neural substrate and to the design of visual stimuli appropriate for an identification of neurons in the fly's brain that may correspond to the various elements in the formal models (Fig. 1C) (Hausen, 1981; Reichardt et al., 1983; Egelhaaf, 1985a,b; Borst, 1991; Egelhaaf and Borst, 1993b). Once the neural elements of the model circuits were known, some of the computations previously characterized formally could be specified in terms of synaptic interactions (Fig. $1 G, H$ ). These hypothetical synaptic interactions were tested experimentally by examining visual responses after functional disablement of specific components of the circuits by pharmacological (Fig. 1D) (Schmid and Bülthoff, 1988; Egelhaaf, 1990; Egelhaaf et al., 1990; Schmid, 1993; Warzecha et al., 1993) and photoablation techniques (Warzecha et al., 1992, 1993). Moreover, with optical recording techniques it is now possible to determine in vivo the intracellular distribution of ions, such as calcium, that may act as charge carriers in activating the cell during motion stimulation or as second messengers in mediating such processes as transmitter release (Borst and Egelhaaf, 1992; Egelhaaf et al., 1993). 
Levels of Analysis
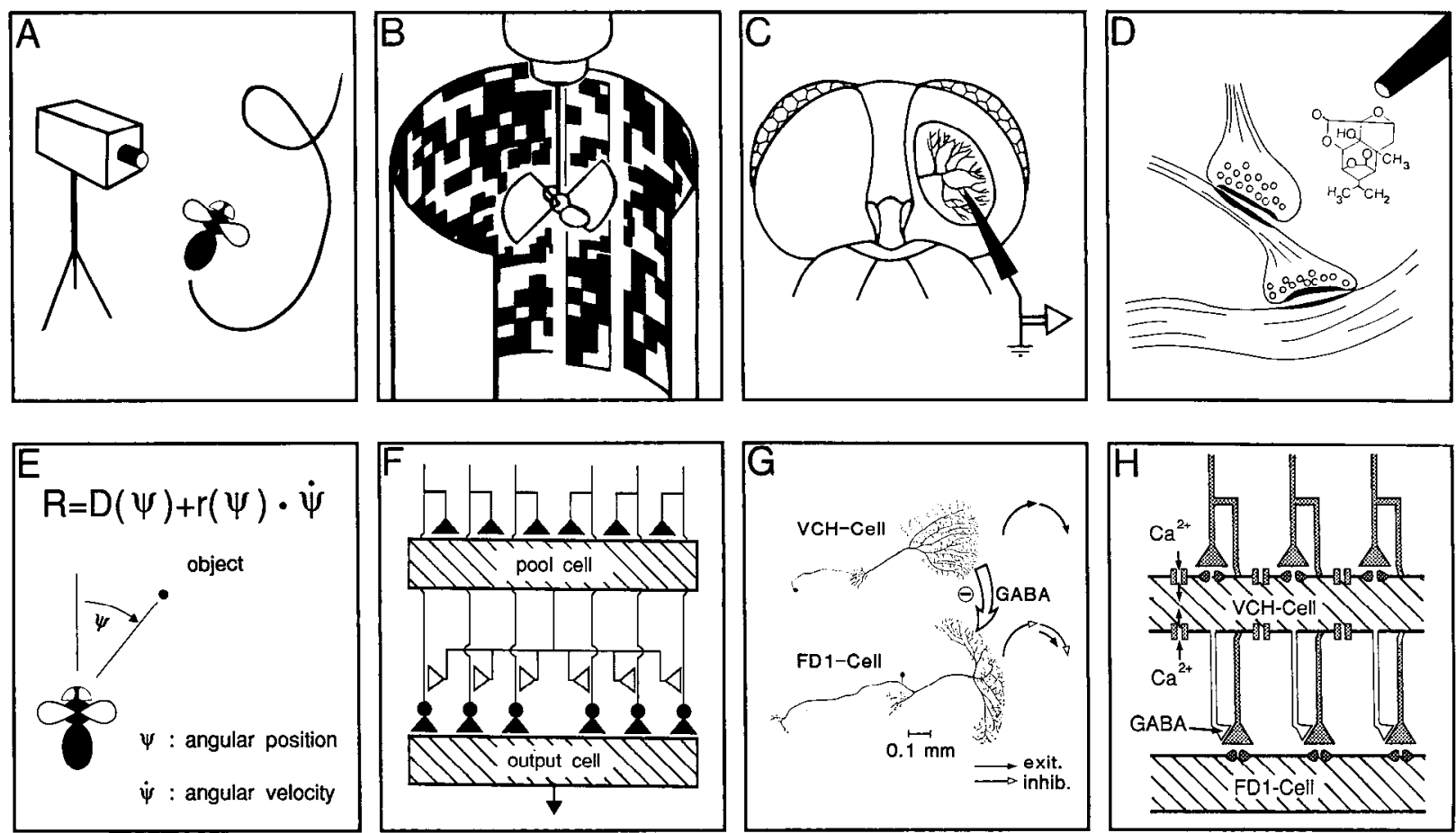

\section{Levels of Explanation}

Figure 1. Levels of analysis $(A-D)$ and explanation $(E-H)$ of visual information processing in the fly. $A$, The complex, visually guided maneuvers in free flight can be recorded with a high-speed camera. $B$, Quantitative input-output relationships of specific components of visual orientation behavior can be established in a flight simulator. The fly is tethered to a device that prevents it from turning while measuring the torque of its turning responses. The fly is surrounded by a cylindrical background panorama of a randomly patterned black-and-white texture and a vertical stripe in front of it covered with the same texture; background and object can be moved together or independently. $C$, A visual interneuron in the third visual neuropil of the fly. The head is shown from its rear aspect, with the margins of the eyes indicated by the facets. An opening is cut into the right half of the head capsule. A neuron stained by intracellular dye injection with a microelectrode is schematically indicated. The activity of individual neurons can be monitored with electrophysiological or optical recording techniques. $D$, Synaptic interactions within neural circuits. Individual neurons can be functionally disabled, either by pharmacological (as indicated) or by photoablation techniques. $E$, Behavioral visual input-motor output analyses form the basis of a phenomenological theory of visual orientation behavior. The torque of the turning response, $R$, of the fly to a moving object can be decomposed into the sum of two terms: one, $D(\psi)$, which depends only on the angular position, $\psi$, of the object, and another that is proportional to the angular velocity, $\psi$, of the object and whose amplitude, $r(\psi)$, depends on the angular position of the object (Reichardt and Poggio, 1976). F, A model circuit that is sufficient to explain gain control of the fly's optomotor system, as well as its ability to detect and fixate a moving object. The circuit consists of two types of neural elements that spatially integrate the output of a retinotopic array of local movement detectors (indicated by black "synapses"; for convenience, only one detector subunit is shown). One of these elements, the "pool cell," was assumed to inhibit presynaptically (indicated by the white "synapses") the input from the movement detectors to the output cell of the circuit. The transmission characteristics between the movement detectors and the output cell are assumed to be nonlinear (indicated by the solid circles on top of the black "synapses"). The movement detector input channels that terminate on the "output cell" are continuous and pass behind the "pool cell" (Reichardt et al., 1983). G, Part of the neural circuit that enables the fly to detect and fixate small moving objects. The output element is the FD1 cell, which responds preferentially to the motion of small moving objects (indicated by small, black arrow); its activity is reduced during binocular wide-field motion (indicated by the arrows with white arrowheads). The FD1 cell is inhibited via GABAergic synapses by the VCH cell, an element excited most strongly by binocular rotatory wide-field motion (indicated by arrows) (after Warzecha et al., 1993). $H$, Details of the hypothetical synaptic interactions between the VCH and FD1 cell. This interaction is dendrodendritic and hence not localized but distributed over the dendritic tree. One dendrite of one VCH and one FDl cell is shown with its local movement detector inputs (shaded in gray). The VCH cell is assumed to inhibit the input channels of the FD1 cell presynaptically via GABAergic synapses. Voltage-dependent calcium channels in the VCH cell arborization transform the movement detector input signals into the output signal (after Egclhaaf et al., 1993).

These various approaches to the computations performed in the fly's visual pathway will be described in more detail in the following.

\section{Course Stabilization and the Object Response}

Flies perform their flight maneuvers much faster than birds, bats, or man-made flying machines. During these maneuvers the retinal images are continually displaced, in a way that is characteristic of the fly's flight trajectory and the layout of its surround (Koenderink, 1986). Hence, retinal image motion contains a wealth of information that may be used in course sta- bilization and object fixation. As was shown by behavioral experiments, flies do resort to motion cues for these purposes.

Two types of behavioral experiments performed with a flight simulator are shown in Figure 2. In both experiments the fly is flying stationarily in space, being tethered to a device that measures the visually induced torque around the vertical body axis. The visual stimuli consist of a cylinder, the "background," surrounding the fly and a stripe, the "object," in front of the cylinder. The background consists of a randomly patterned blackand-white texture. The stripe is covered by the same texture as the background (Fig. $1 B$ ) or is solid black. Both object and 
background can be moved coherently or incoherently with respect to each other. The flight simulator can be operated in two basically different modes. Either the fly is presented with stimuli that are controlled only by the experimenter-in this case, the fly's responses do not influence the visual input to its retina ("open loop mode"), in contrast to natural flight conditions where they do-or the fly's turning responses feed back onto both the object and the background, and hence on the retinal input ("closed loop mode"), thus simulating the natural flight situation where the fly influences its retinal input by its own responses.

In the open loop experiment shown in Figure $2 A$, the cylindrical background and a randomly patterned stripe, whose mean position is to the right of the fly's forward direction, are oscillated sinusoidally. During in-phase oscillations of object and background, the fly tries to turn in order to follow the motion of the panorama. Under the conditions of free flight, this socalled "compensatory optomotor response" would reduce the retinal velocity of the panorama. As soon as object and background oscillate out of phase, however, an "object fixation response" is superimposed on the optomotor response. The fly exerts an additional torque to try to turn toward the object. In free flight, the fly thus would fixate the object in the frontal visual field. The extent to which optomotor and object fixation responses are elicited depends on the phase relations between object and background motion, as well as on the dynamical features and strengths of the stimuli (Reichardt and Poggio, 1979; Bülthoff, 1981; Reichardt et al., 1983, 1989; Egelhaaf, 1985a, 1987, 1989).

In the closed loop experiment shown in Figure $2 B$, the object (a black stripe) is subjected to a constant force that, in the open loop mode, would drive it with a constant velocity ("open loop velocity") around the fly. Since in the closed loop mode the torque exerted by the fly counteracts the driving force, the object is fixated near the fly's frontal midline. However, as a consequence of fixating a moving object, the background is continually displaced in the opposite direction. This setup thus simulates free flight, where the fiy tracks an object moving at a constant speed in a given direction. However, the object is not fixated exactly in the frontal midline but is displaced laterally. This "error angle" increases with increasing open loop velocity of the stripe and depends also on the contrast of the background texture. This texture dependence is the consequence of the optomotor response that is induced by the displacements of the background that are an inevitable consequence of object fixation in the closed loop mode. Since this optomotor response countcracts the object fixation response, the error angle is increased when the contrast of the background texture increases (Fig. 2B). Thus, the error angle of the object is a compromise between two opposing response components (Reichardt, 1973; Reichardt and Poggio, 1975, 1976; Virsik and Reichardt, 1976). It should be noted that these conclusions are based on the mean error angle of the object. Analysis of the temporal fine structure of the responses in the closed loop mode reveals that fixation of the object may be accomplished by sequences of brief torque pulses (Heisenberg and Wolf, 1984).

\section{Algorithms underlying Visual Information Processing in the Fly}

The performance of the fly under open and closed loop conditions can be well described by a phenomenological theory that relates the behavioral response to the position of the object in
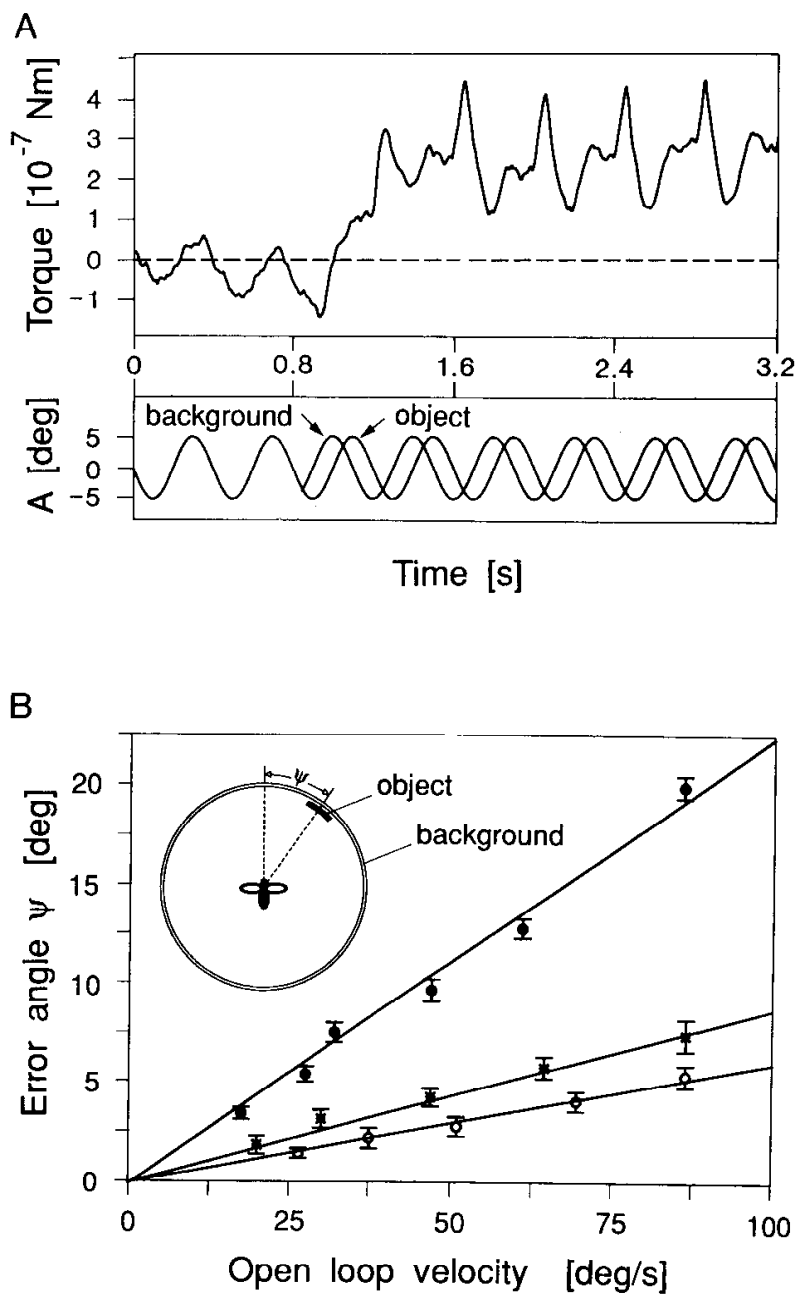

Figure 2. Compensatory optomotor and object fixation response in the flight simulator. $A$, Open loop mode: turning response of the fly to in-phase and out-of-phase motion of background and object. Lower trace, Simultaneous oscillations of the background and a randomly patterned object (Fig. 1B) about a mean position, initially in phase and later with a phase shift of $90^{\circ}$. The mean position of the object is $30^{\circ}$ to the right of the fly's forward direction. During in-phase motion, the torque response of the fly oscillates at the frequency of the pattern. Under free-flight conditions, this compensatory optomotor response would reduce the velocity of the stimulus pattern on the fly's retina. During out-of-phase motion, the fly exerts an additional mean rightward torque response, indicating that it has detected and tries to fixate the object (redrawn from Egelhaaf, 1985c). $B$, Orientation toward an object (a black vertical stripe) subjected to a constant force that, under open loop conditions, would move the object with a constant velocity ("open loop velocity") around the fly. The object is not fixated exactly in the frontal midline but is slightly displaced ("error angle"). The error angle increases with increasing open loop velocity. In addition, the error angle depends on the texture of the background panorama. It is smallest if there is no texture at all (bottom curve) and becomes larger with increasing texture contrast $(33 \%$, middle curve; $56 \%$, top curve). This contrast-dependent increase of the error angle is the consequence of a corresponding increase in the strength of the compensatory optomotor response induced by the background panorama. Redrawn from Virsik and Reichardt (1976).

the visual field, as well as to the velocity of object and background (Reichardt and Poggio, 1975, 1976; Virsik and Reichardt, 1976). This theory also takes physical constraints of the fly into account, such as inertia and aerodynamic friction. According to the phenomenological theory of fly visual orientation, 
the behavioral response can, to a first approximation, be decomposed into two components. One component, the "direction-sensitive" component, corresponds to the compensatory optomotor response and depends on the velocity of the stimulus motion; it changes sign when the stimulus reverses its direction of motion. The other response component, the "direction-insensitive" component, corresponds to the object fixation response and is independent of the direction of motion (Fig. $1 E$ ) (Poggio and Reichardt, 1976). Although the phenomenological theory is not intended to explain visual orientation behavior of the fly in general, it does predict at least the two response components under a wide range of stimulus conditions in tethered flight (Reichardt and Poggio, 1975, 1976; Virsik and Reichardt, 1976) and even under free-flight conditions (Land and Collett, 1974; Bülthoff et al., 1980; Wagner, 1986a,b).

Nevertheless, the phenomenological theory does not immediately tell us how the direction-sensitive and the directioninsensitive response components are computed in the fly's brain. It cannot even be taken for granted that the formal decomposition of the overall behavioral reactions into a direction-sensitive compensatory optomotor response and a direction-insensitive object fixation response are reflected by specialized neural subsystems with just those properties. For instance, a behavioral response component that does not depend on the direction of motion can be the result of neural subsystems with a varying degrec of direction sensitivitics. A single direction-insensitive neuronal system represents just one extreme of the range of possibilities, with the other extreme given by the superposition of two direction-sensitive neural subsystems with opposite polarities.

For a long time, conflicting experimental evidence was discussed concerning the algorithms that underlie the optomotor and object fixation responses in the fly. Initially, it had been assumed that the decomposition of the behavioral response into a direction-sensitive component and a direction-insensitive component has a direct counterpart in the fly's brain (Reichardt and Poggio, 1976). Further behavioral experiments (Wehrhahn and Hausen, 1980; Reichardt et al., 1983) led to the proposal that both components are due to a single system equipped with a gain control mechanism that makes the response virtually independent of the spatial extent of the stimulus pattern but still allows encoding of other stimulus parameters. The gain control properties that are required for such a system have been accounted for by a model network consisting of retinotopic movement detectors (see below) and two neurons that spatially integrate the output of arrays of these detectors (Fig. $1 F$ ). The main functional feature of the model circuit is that one of the integrating neurons, the "pool cell," inhibits presynaptically the retinotopic input of the other integrating neuron ("output cell"). When the parameters characterizing the synaptic transfer characteristics were chosen appropriately, this network could account for the experimentally observed behavioral data that were available at the time the model was proposed (Poggio et al., 1981; Reichardt et al., 1983). When the retinal images of both eyes move coherently, the model circuit leads to an optomotor response. However, when there is an object in front of one of the eyes moving relative to the background, the circuits subserving both eyes are stimulated asymmetrically, which leads to an object fixation response. Owing to the gain control properties of the circuit, already relatively small objects induce sufficiently large fixation responses to override the optomotor response.
Subsequent behavioral experiments (Egelhaaf, 1985a, 1987, 1989; Reichardt et al., 1989) revealed, however, that optomotor and object fixation responses must be due to the joint action of two parallel neural pathways. This inference was consistent with the behavioral deficits observed in neurogenetic (Götz, 1983; Heisenberg and Wolf, 1984; Bausenwein et al., 1986) and neuronal ablation studies (Geiger and Nässel, 1982; Hausen and Wehrhahn, 1990). The two parallel pathways are tuned to either of two different kinds of retinal image motion patterns. The neural pathway mcdiating the optomotor response ("large-field system") passes mainly signals arising from slow velocity changes of extended stimulus patterns. The neural pathway mediating object fixation passes mainly signals arising from fast velocity changes of small objects moving relative to a stationary or moving background ("small-field system"). Hence, according to their spatial and dynamical response properties, the relative contribution of both pathways to optomotor and object fixation responses is not invariant but depends on the velocity and spatial extent of background and object (Egelhaaf, 1987, 1989; Reichardt et al., 1989).

\section{Identification of the Neural Pathways}

The transformation of the visual input to the eyes into an appropriate motor output is the result of particular biophysical properties of nerve cells and the pattern of their connections. Figure 34 summarizes schematically those components of the fly's nervous system that are most relevant in the present context. The retinal image is initially transformed in the first and second visual neuropil by successive layers of retinotopically organized columnar nerve cells. The retinotopic order is abandoned at the level of the third visual neuropil, where large-field neurons integrate the output from many columnar neurons. These "tangential cells" connect either to other brain areas or, via descending neurons, to the motor control centers. All tangential cells respond preferentially to motion in a particular direction. Due to their anatomic and physiological invariance, the tangential cells can be identified individually in each animal. This identifiability is ideal for the experimental analysis of neuronal networks and their computations. The tangential cells are of importance in the present context, because they extract different types of retinal motion patterns and play a decisive role in controlling behavioral responses, such as optomotor and object fixation responses (for general reviews about the visual system of the fly, see Strausfeld, 1976, 1989; Hausen, 1984; Hardie, 1989; Hausen and Egelhaaf, 1989).

Figure $3 B$ shows the anatomy of two types of output neurons of the third optic neuropil: the three elements of the "horizontal system" (HS) cells and one of the "figure detection" (FD) cells, the "FD1 cell." These output neurons appear to fecd into the pathway of optomotor (Heisenberg et al., 1978; Geiger and Nässel, 1981, 1982; Hausen, 1981; Egelhaaf, 1985c; Wehrhahn, 1985; Hausen and Wehrhahn, 1990) or object fixation responses (Egelhaaf, 1985a-c; Egelhaaf et al., 1988). The response of the HS cells to moving visual stimuli increases with increasing spatial extent of the stimulus pattern (Fig. 3C) (Hausen, 1982a,b). In contrast, the FD cells respond most intensively to the motion of a small object in their extended receptive field, whereas their activity is greatly reduced during large-field motion (Fig. 3D) (Egelhaaf, 1985b). HS and FD cells thus differ considerably in their spatial response characteristics and match the respective properties of the optomotor and object fixation response. However, HS and FD cells do not differ with respect to their dynamic 


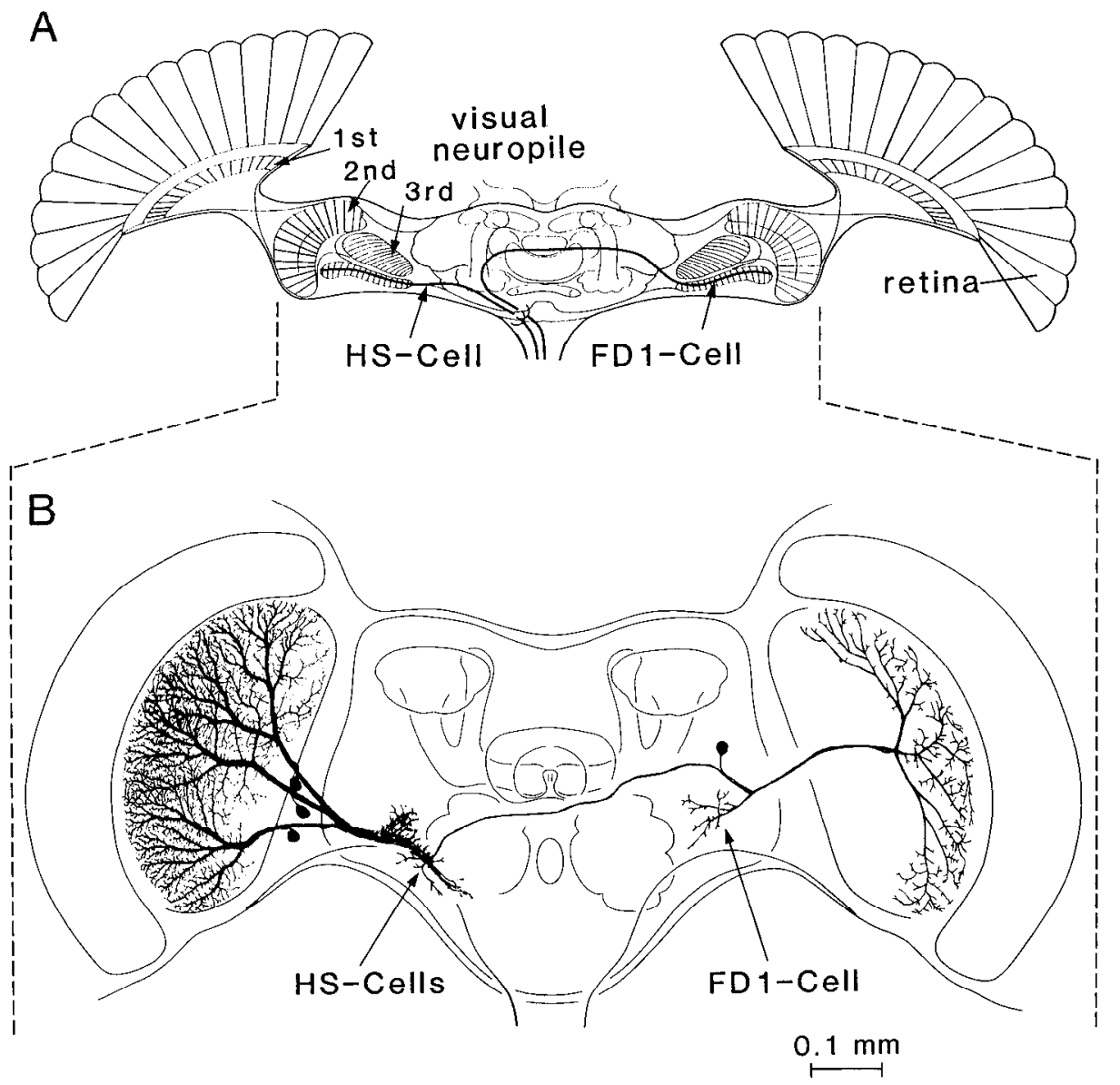

C

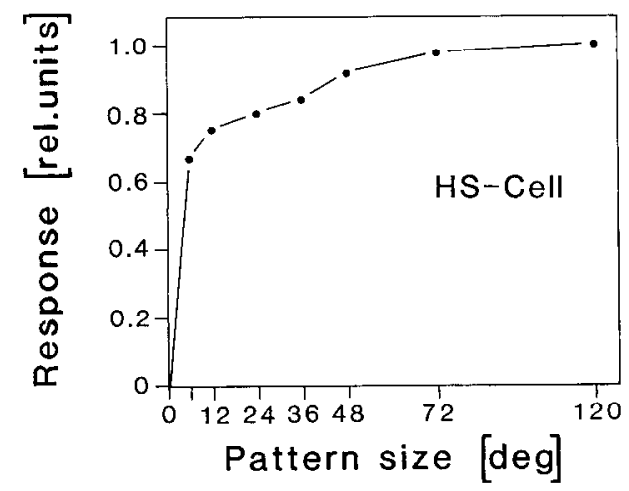

D

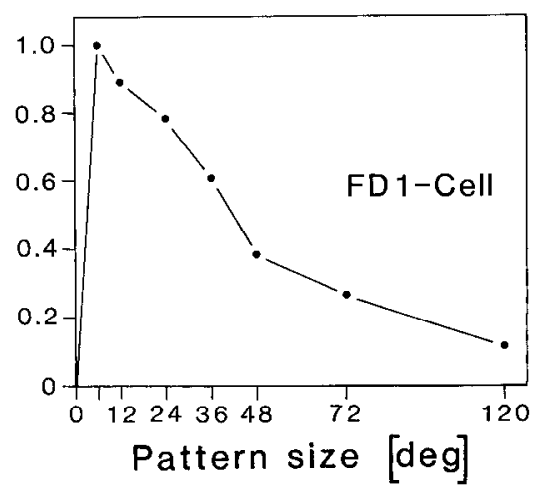

Figure 3. Overview of the brain of the fly and the main output elements of the visual system that feed the pathways mediating optomotor and object fixation responses. $A$. Horizontal cross section showing the retina, the three visual neuropils, and the central brain. Indicated is the retinotopic organization of the visual system. Two tangential cells in the posterior part of the third visual ncuropil are indicated by thick lines orthogonally oriented to the columns (FD1 cell in the right half and HS cell in the left half of the brain). The FD1 cell connects to descending neurons in the contralateral half of the brain; the HS cells, to descending neurons in the ipsilateral half (at synapses indicated by arcs). The descending axons (indicated by lines leaving the brain) are assumed to project to the motor control centers in the thoracic ganglia (not shown) (modified from Hausen, 1984). $B$, Frontal projection of arborizations of the three HS cclls (shown in the left optic lobe) and one of the FD cells, the FD 1 cell (shown in the right optic lobe) (HS cells courtesy K. Hausen; FDl cell from Egelhaaf, 1985b). $C$ and $D$, Dependence of the mean response amplitude of an HS cell $(C)$ and an FD1 cell $(D)$ on the size of the stimulus pattern. The stimulus pattern was a random texture that covered part of the background cylinder. Its horizontal extent was varied; the remaining cylinder was homogeneously white (for details, see Egelhaaf, 1985a). The HS cell reaches its maximum response when the moving stimulus pattern is large, whereas the FD1 cell responds maximally when the stimulus pattern is small ( $C$ modified from Egelhaaf and Borst, 1993b; $D$ modified from Egelhaaf, 1985c). response characteristics, as do the corresponding behavioral responses. The appropriate temporal filtering, therefore, takes place at a processing stage postsynaptic to the FDl and HS cells (Egelhaaf, 1987, 1989; Reichardt et al., 1989).

\section{Mechanisms of Motion Computation}

What is the nature of the computations carried out by these two motion pathways that transform the visual input of the eyes into an appropriate motor output? The computations consist essentially of three steps: (1) primary processing of motion computation by arrays of local movement detectors, (2) spatial integration of the output of ensembles of local movement detectors by neurons with large dendritic fields, and (3) interactions be- tween these spatially integrating neurons. Sophisticated transformations of the visual input can emerge from combinations of these simple computations.

\subsection{Local movement detectors}

Motion in the fly's normal surround does not usually have the same direction and speed in different parts of the visual field. In the first step of motion analysis, a representation of the local velocity vectors is computed in parallel by movement detectors that cover the entire visual field in a retinotopic organization. Based on a behavioral analysis of insect optomotor responses, the formal "correlation model" of local movement detectors was proposed long ago (Reichardt, 1961; for review, see Borst 


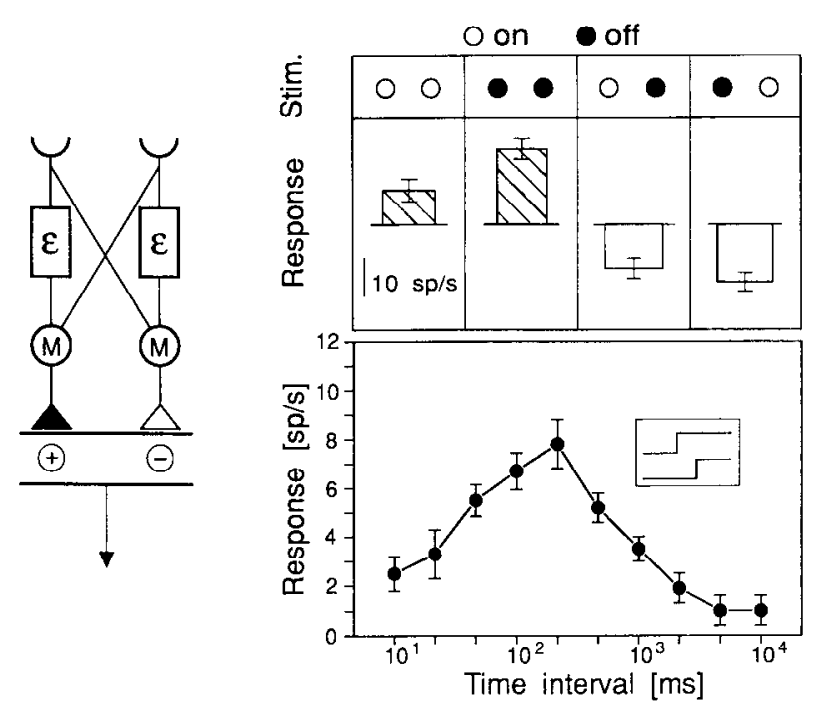

Figure 4. The mechanism of local motion detection. Left, Movement detector of the correlation type. In its simplest form, its input is provided by the light intensities as measured by two detector subunits at two points in space. In each detector subunit, its input signal is multiplied $(M)$ with that of the adjacent subunit after one of them has been delayed by a low-pass filter $(\epsilon)$. The output product of one of the mirror-symmetrical subunits $(-)$ is then subtracted from the other $(+)$ to provide the final output signal of the detector. Top right, Mean direction-sensitive response component of a tangential cell to apparent motion stimuli. The cell was stimulated with four types of apparent motion sequences in its preferred direction: on-on, off-off, on-off, or off-on (brightness increases and decreases are indicated above the responses by white and black circles, respectively). The interval between the brightness changes was $500 \mathrm{msec}$. The responses (presented as spikes/second) to apparent motion sequences with brightness changes of the same polarity are positive and those with a different polarity are negative, as is predicted for a movement detector with a multiplicative interaction of its input channels (for details, see Egelhaaf and Borst, 1992). Bottom right, Mean amplitude of the direction-sensitive response component of a tangential cell as a function of the time interval between the brightness changes of an apparent motion on-on sequence (indicated by the inset). The response amplitude increases with increasing time interval, reaches a maximum, and then decreases again. Data redrawn from Egelhaaf and Borst (1992).

and Egelhaaf, 1993a). In its simplest form (Fig. 4), such a local movement detector is composed of two mirror-symmetrical subunits. In each subunit, the inputs from neighboring points in visual space interact by a multiplication after one of them has been delayed by a low-pass filter. The final detector response is obtained by subtracting the two subunit outputs. On the average, each detector subunit computes a spatiotemporal crosscorrelation of two retinotopically contiguous input signals. This formal opcration leads to a uscful motion cstimatc, bccause during pattern motion the detector injut lines receive, with a certain temporal delay, the same input. Thus, the detector subunits respond directionally selectively to motion. However, they may also respond to a correlated input that is independent of the direction of motion, such as changes in brightness. These direction-insensitive response components are eliminated by the subtraction stage. The final output of a local movement detector signals motion in opposite directions with the same amplitude, but a different sign. Only a few elaborations are necessary to adapt the basic form of the correlation model as shown in Figure 4 to account for the specific features of the fly's motion detection system (for review, see Egelhaaf and Borst, 1993a).
One line of evidence for a multiplicative interaction of the two input signals of the movement detector comes from experiments where "apparent motion" stimuli were used. Rather than smoothly displacing the stimulus, motion is mimicked here by either increasing or decreasing the brightness in front of the two detector input lines in a stepwise manner, one after the other. Four different stimulus combinations are possible. Both signals can change with the same polarity, thereby mimicking motion of an edge. Alternatively, both signals can change their brightness with a different polarity, mimicking a situation that can hardly occur in reality; that is, motion of an edge that simultaneously reverses its contrast. The responses to these apparent motion stimuli of a directionally sensitive motion detector neuron in the fly's optomotor pathway are shown in Figure 4. In accordance with behavioral (Hassenstein, 1958; Reichardt, 1961) and earlier electrophysiological results (McCann, 1973; but see Franccschini ct al., 1989), the ncuron is activated by apparent motion with contrast transitions of the same polarity, whereas it is inhibited by contrast changes of different polarity (Egelhaaf and Borst, 1992). The outcome of this experiment is predicted from a multiplicative interaction of the two input signals of the local movement detector: multiplication of signals with the same polarity leads to positive responses, whereas multiplication of signals with different polarity leads to negative responses.

Since in each detector subunit one of the input signals is delayed before it interacts with the other, the detector response is maximal when the pattern velocity matches the delay time. Hence, if a directionally selective motion-sensitive cell is stimulated with apparent motion, the response amplitude first increases with the increasing time interval between the brightness changes at neighboring locations in space, reaches an optimum, and then decreases again (Fig. 4) (McCann, 1973; Franceschini et al., 1989; Schuling et al., 1989; Egelhaaf and Borst, 1992).

The correlation model was one of the first explicit formal algorithms developed for sensory information processing. It still represents one of the most successful models in computational neuroscience because it has provided a valid conceptual basis for understanding motion detection not only in insects but also in many vertebrates, including humans (for review, see Borst and Egelhaaf, 1989; Sekuler et al., 1990).

\subsection{Spatial integration of local motion detectors}

In the second step of motion analysis, the output of the local retinotopic movement detectors is pooled. This is accomplished in the dendrites of the tangential cells in the third visual neuropil.

An optical technique for recording changes in neuronal polarization has made it possible to visualize the retinotopic input to individual tangential cells in the living fly, by injecting single neurons with an ion-selective dye as an activity marker. Optical recording in vivo is possible because the tangential cells arborize within a thin superficial layer of the brain (Borst and Egelhaaf, 1992). As shown by the records of Figure 5, motion in the dorsal or ventral part of the receptive field leads to preferential activity in the dorsal or ventral dendritic branches, respectively. Hence, information about motion in the visual field is projected on the dendritic tree of the tangential cells as a two-dimensional image.

Two types of retinotopic input elements, one inhibitory and the other excitatory, converge onto the dendritic tree of the tangential cells. There is evidence that these input elements correspond to the two subunits of the formal movement detector model (Egelhaaf et al., 1989; Borst and Egelhaaf, 1990). In combined pharmacological and electrophysiological experiments it 


\section{HSE-Cell}

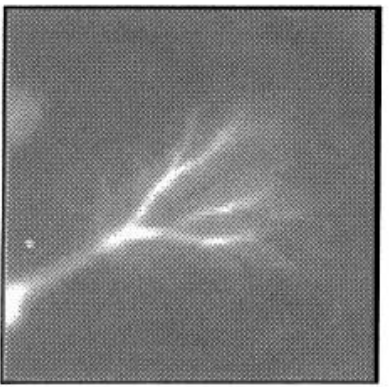

A

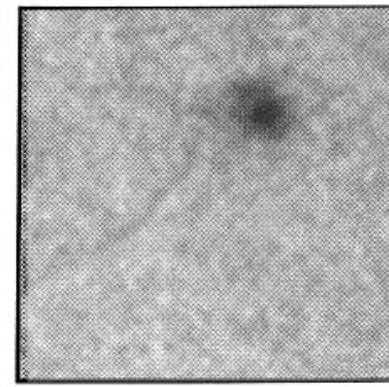

B
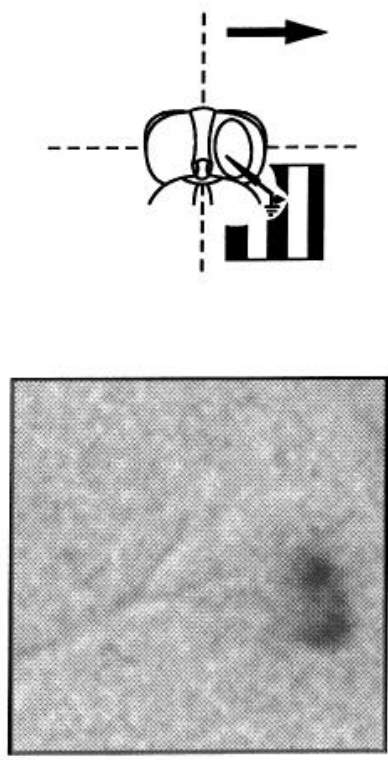

C
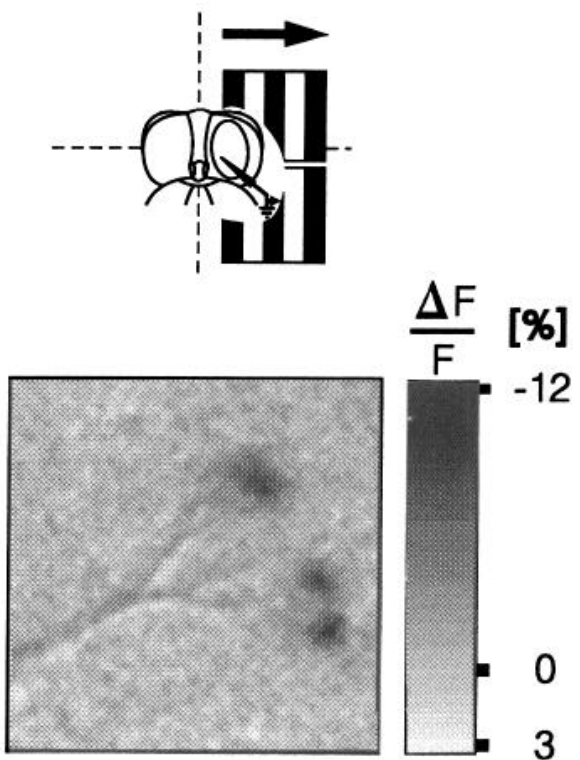

$-12$

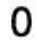

3

Figure 5. Retinotopic input to the tangential cells in the third visual neuropil: Optical recordings taken from an HSE cell. $A$, Fluorescence image of the cell in the living fly stained with the calcium sensor fura- 2 evoked by $380 \mathrm{~nm}$ excitation. $B-D$, Change in relative fluorescence $(\Delta F / F)$ of the same cell at $380 \mathrm{~nm}$ excitation after $9 \mathrm{sec}$ of motion in the preferred direction in the dorsal $(B)$, ventral $(C)$, and both $(D)$ parts of the receptive field. The stimulus conditions are shown schematically at the top of each panel; they show the fly's head from the rear aspect with an electrode inserted into the right half of the brain facing the respective stimulus pattern. The relative fluorescence changes that reflect a change in free cytosolic calcium in the dendrites are coded by a gray level, with darker grays indicating larger fluorescence changes. Negative fluorescence changes correspond to an increase in calcium concentration. Data from Borst and Egelhaaf (1992).

could be shown that the inhibitory input elements are likely to release GABA as a neurotransmitter (Egelhaaf et al., 1990), whereas, as is indicated by preliminary in vitro experiments, the excitatory elements may release $\mathrm{ACh}$ (Brotz et al., unpublished observations).

Because the reversal potentials of the EPSP and IPSP are about equally distant from the resting potential of the tangential cell, the postsynaptic interaction between the two types of input is fairly linear and therefore corresponds to a simple subtraction (Haag et al., 1992). As a consequence, the tangential cells respond with graded membrane potential changes of about the same amplitude, but a different sign, to motion in opposite directions. As was explained above, this design of the tangential cells leads to a movement detection system that responds optimally to motion and only much less to brightness changes of stationary stimuli (Egelhaaf et al., 1989; Borst and Egelhaaf, 1990).

Because the tangential cells spatially integrate the output of many retinotopic local movement detectors, they are sensitive to motion in large parts of the visual field. Hence, their response amplitude should increase with an increasing spatial extent of the stimulus pattern. Both the HS and FD cells as key elements in the neural pathways mediating the optomotor and object response deviate from this simple expectation. As is shown in the following section, the HS cells exhibit gain control properties, whereas the FD1 cell responds strongest to relatively small objects, rather than to extended stimuli (Fig. $3 D$ ).

\subsection{Gain control in the neural pathway mediating compensatory optomotor turning responses}

As is shown in Figure $3 C$, the response amplitude of the HS cells increases with increasing stimulus pattern size, finally lev- eling off at a maximal response plateau. This is a general feature of those fly tangential cells that respond preferentially to widefield motion. The maximal response plateau cannot be the result of a simple saturation of the output, since it depends on pattern velocity (Fig. 6A) (Hausen, 1982b; Haag et al., 1992). Hence, it appears that the gain of the optomotor pathway is controlled by stimulus parameters such as pattern velocity. As a consequence, changes in stimulus parameters, such as pattern velocity, may lead to changes in the response amplitude and thus can be encoded by the cell, even if the response amplitude no longer changes with the size of the stimulus pattern (Reichardt et al., 1983).

In the original explanation of the gain control mechanism it was assumed that the gain of the pathway is adjusted by the interactions within a network of nerve cells (Fig. $1 F$ ) (Poggio et al., 1981; Reichardt et al., 1983). Recent experiments have indicated, however, that gain control arises from intrinsic properties of the tangential cells and their movement detector input elements (Haag et al., 1992).

Figure $6 B$ summarizes the essentials of the current explanation of the gain control mechanism. When the stimulus pattern moves in a direction that induces the largest response amplitudes ("preferred direction"), not only are the excitatory input elements of the tangential cells activated, but also, though to a lesser extent, the inhibitory input elements (Borst and Egelhaaf, 1990). This means that the response level of the cell that is approached with large stimulus patterns does not represent the reversal potential of the excitatory synaptic input. Rather, it tends to approach a polarization level that depends on the relative contribution of the inhibitory input channel to the overall response, which depends on stimulus velocity (Egelhaaf et al., 1989; Borst and Egelhaaf, 1990). In this explanation of the gain 
A

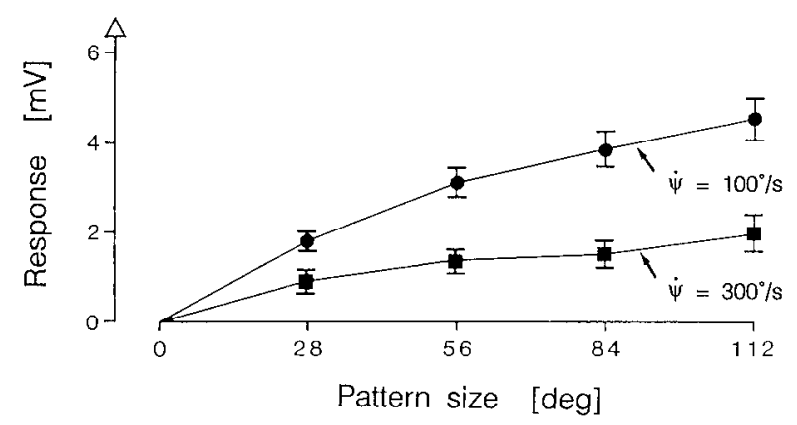

$B$

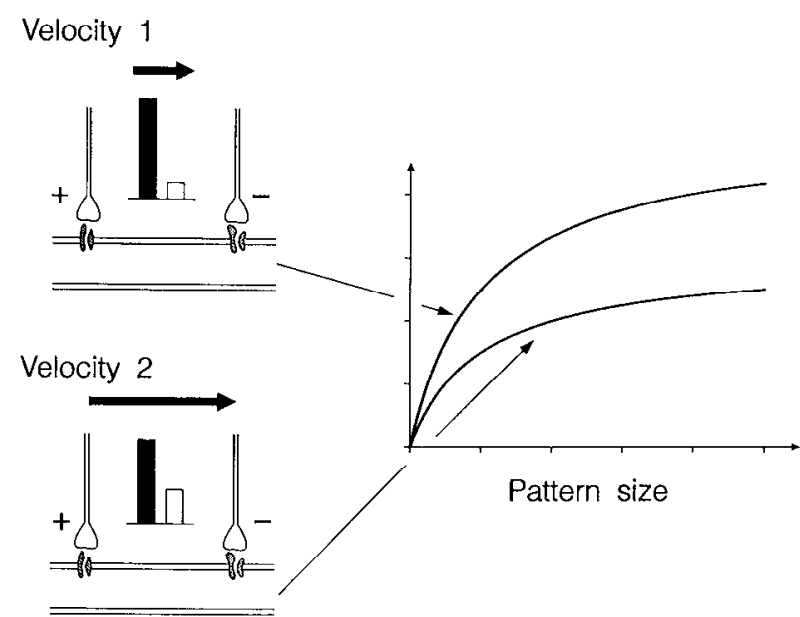

Figure 6. Gain control in the tangential cells of the third visual neuropil optimally responsive to wide-field motion. $A$, Average response of a tangential cell to a pattern moving at two different velocities $\dot{\psi}$ higher than the neuron's optimal velocity (upper curve, 100 degrees/sec; lower curve, 300 degrees/sec) as a function of pattern size. The response approaches a maximum plateau that is lower for the higher velocity. Modified from Haag et al. (1992). $B$, Model simulation of the movement detector output and a tangential cell. Left, The output channels of the two subunits of a local movement detector are shown terminating on the dendrite of a tangential cell. The amplitudes of responses of the subunits during motion in the preferred direction are displayed for two pattern velocities (indicated by the arrows above the detector subunits). Not only the excitatory $(+)$ input channel is activated (black bar) but also, though to a lesser extent, the inhibitory $(-$ ) one (white bar). The relative contribution of both subunits depends on the pattern velocity. Right, When the number of activated movement detectors increases by increasing the size of the stimulus pattern, the response tends to approach a maximum plateau level. This plateau level depends on the relative activity of the excitatory and inhibitory detector subunits, which in turn is set by the stimulus velocity. As a consequence of gain control, the response amplitude of the cell becomes relatively independent of the size of the stimulus pattern but still varies with pattern velocity.

control mechanism of the optomotor pathway, the tangential cells were implicitly assumed to be isopotential. More realistic computer simulations in which the movement detector input was distributed over a dendritic tree and weighted according to its electrotonic distance from the axon led essentially to the same results (A. Borst and M. Egelhaaf, unpublished observations).

It should be noted that no active membrane properties had to be assumed in these model simulations to account for the gain control mechanism of the optomotor pathway. However, there are various lines of evidence showing that the graded membrane potential changes that are generated in the dendrite of the tangential cells upon motion stimulation do not simply reflect the summated postsynaptic potentials of the movement detector input clcments. Rathcr, optical recording and electrophysiological experiments demonstrate that there are voltagegated calcium channels in the dendrites of the tangential cells that may amplify the postsynaptic potentials in a graded way (M. Egelhaaf and A. Borst, unpublished observations).

In any case, the tangential cells in the third visual neuropil of the fly are able to perform tasks such as automatic gain control that are relatively complex from a computational point of view and have previously been attributed to interactions with other tangential neurons. This means that these cells are not simple integrators of their synaptic input but complex devices that compute information that is decisive for the behavioral performance of the animal.

\subsection{Network interactions tuning the neural pathways that mediate the object response}

Network interactions with other tangential cells play an important role in tuning cells to some retinal motion patterns. These network interactions are the third major step of motion computation in the fly's brain. One such network interaction occurs in the pathway that enables the fly to detect and fixate small moving objects. As an output element of this pathway, the FD1 cell (Fig. $3 B, D$ ) responds best to a small object moving relative to its background, whereas its activity is much reduced during coherent large-field motion in front of either eye (Egelhaaf, $1985 \mathrm{~b}$ ). This spatial tuning suggests the following input organization of the FD1 cell: (1) it integrates, as do the other tangential cells, the signals provided by an array of local motion detectors; (2) to prevent it from responding to large-field motion, it is inhibited by an element that is most sensitive to large-field motion in the FD1 cell's preferred direction (Egelhaaf, 1985c).

This inhibitory element was recently identified by inactivating potential candidates for that role and by determining the consequences for the response properties of the FDI cell. The inactivation was achieved either pharmacologically by application of a GABA antagonist (Fig. 1D) (Egelhaaf, 1990; Warzecha et al., 1993) or by specifically photoablating individual cells after injecting them with a photosensitizing fluorescent dye (Warzecha et al., 1992, 1993). It turned out that only when the GABAcrgic VCH cell was ablated did the specific tuning of the FDl cell to small moving objects disappear (Fig. 7). Hence, only a single inhibitory neuron, the VCH cell, is likely to he responsible for the specific spatial tuning of the FDl cell, allowing the fly to discriminate objects from their background (see Fig. $1 G$ ).

However, knowing the wiring diagram of a neural circuit is not sufficient for understanding how it processes information. Rather, its computational properties may also critically depend on the geometrical and biophysical properties of its constituent elements, as well as on the transfer characteristics of the involved synapses.

The output of the tangential cells in the third visual neuropil of the fly does not exclusively encode a single stimulus parameter. For instance, the response amplitude may increase with increasing size of a moving pattern as well as with increasing speed at which the pattern is moving. Since this is also true for the $\mathrm{VCH}$ cell, one may expect that the inhibition it excrts on the FD1 cell increases also with both pattern size and pattern velocity. However, the response of the FD1 cell is only reduced when the pattern size increases, but not when the pattern velocity increases. Hence, the different stimulus parameters are 
Laser Irradiation
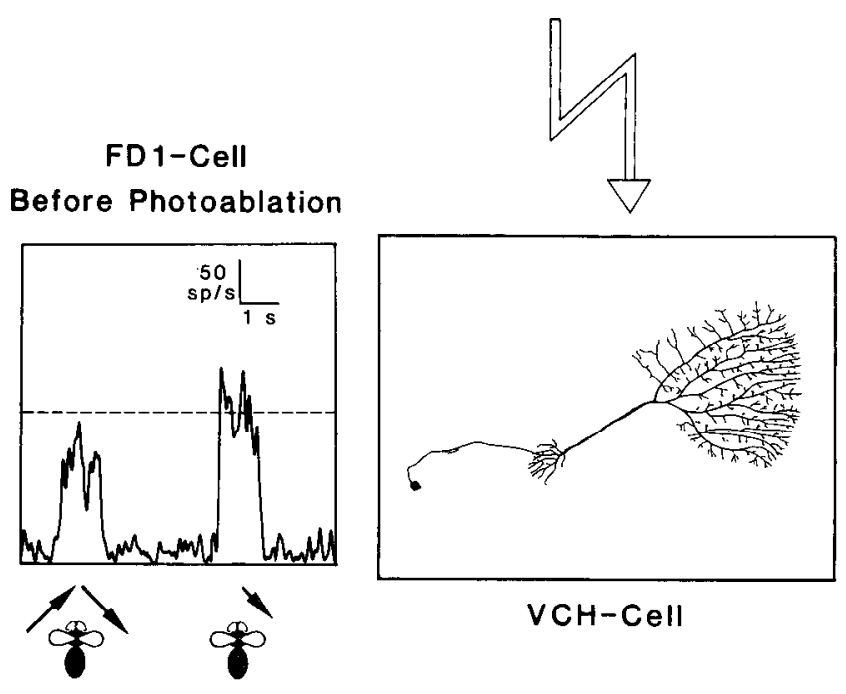

$\mathrm{VCH}-\mathrm{Cell}$
FD 1-Cell After Photoablation

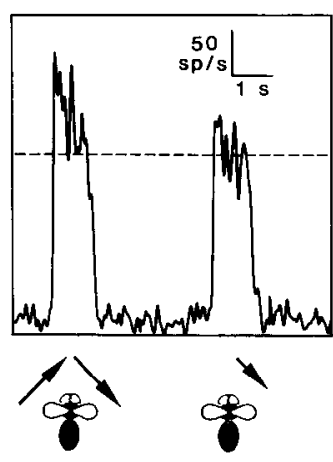

Figure 7. Role of the VCH cell in tuning the FD1 cell to the motion of small moving objects: spike frequency (spikes/ $\mathrm{sec})$ histograms of the responses of an FD1 cell to rotatory binocular large-field motion and small-field motion in front of the right eye (arrows under the panels indicate the directions of motion) before and after photoablation of the $\mathrm{VCH}$ cell. $\Lambda$ reconstruction of the main branches of a VCH cell from a wholemount preparation is shown in the middle panel. The cell was filled with the fluorescent dye 6-carboxy-fluorescein. Before the preparation was irradiated with a laser beam, the FDl cell responded in its normal way, that is, with a spike frequency that is higher during small-field than during large-field motion. After photoablation of the $\mathrm{VCH}$ cell, the FD1 cell responds more vigorously to large-field than to small-field motion. The dashed line indicates the mean response level during small-field motion. Data from Warzecha et al. (1993). disambiguated to some extent by the circuit. Two different explanations of how this can be achieved have been proposed.

The first explanation (Egelhaaf, 1985c) was based on a previously proposed network model for the optomotor and object fixation response (Fig. 1E) (Poggio et al., 1981; Reichardt et al., 1983). According to this model, the output signal of the VCH cell depends on pattern size and other stimulus parameters, such as pattern velocity. The $\mathrm{VCH}$ cell is assumed to inhibit presynaptically the movement detector input to the model FD1 cell. The resulting input signals of the FD1 cell are then transformed into the postsynaptic response by a nonlinearity. With several simplifying assumptions the response amplitude of both the $\mathrm{VCH}$ and FD1 cell can be described by simple formulas. Assume that both cells summate the output signals of $N$ local movement detectors. Their response amplitude $x$ is proportional to pattern velocity. If the summated synaptic input of the VCH cell is transformed by a saturation nonlinearity, which is approximated by the exponent $q$ with $0<q<1$, then we obtain for the response of the $\mathrm{VCH}$ cell

$$
R_{\mathrm{vCH}}=(N \cdot x)^{a} .
$$

A shunting inhibition was assumed as a specific type of inhibition provided to the movement detector input of the FD1 cell. This means that the reversal potential of the inhibitory ion is close to the resting potential of the postsynaptic element. As follows from the equation for an electrical equivalent circuit of a passive patch of membrane, the signal carried by the movement detectors becomes essentially divided by the inhibitory input (Reichardt et al., 1983). With a shunting inhibition coefficient $\beta$ (the formal equivalent of the leak conductance of the cell), each of the $N$ input signals to the model FD1 cell turns into $x /\left[\beta+(N \cdot x)^{q}\right]$. With $n$ describing the nonlinear transmission characteristic of the synapses between the movement detectors and the FD1 cell, the response amplitude of the FD1 cell is given by

$$
R_{\mathrm{FD} 1}=N \cdot\left\{x /\left[\beta+(N \cdot x)^{a}\right]\right\}^{n} .
$$

The model FD1 cell exhibits small-field tuning only if $n \cdot q>$
1. Hence, $n$ represents an expansive nonlinearity (Reichardt et al., 1983, 1989; Egelhaaf, 1985). According to this model, the response amplitude of the $\mathrm{VCH}$ cell, and thus the net presynaptic inhibition provided to the input channels of the FD1 cell, increases with both increasing size and velocity of the stimulus pattern. Thus, when the pattern size exceeds a certain limit, the response of the FD1 cell continuously decreases with increasing pattern size. However, owing to the expansive nonlinearity of the synapses between the movement detectors and the FD1 cell, the FD1 cell signal still increases with pattern velocity, because the transmission characteristic of its input synapses overrides the inhibitory effect exerted by the VCH cell. This type of mechanism only works if it is assumed that the synapses that connect the local movement detectors with the FDI and VCH cell have different transmission characteristics (Borst and Egelhaaf, 1993b). However, photoablation of the VCH cells provides good evidence that this is not the case. An expansive nonlinear transmission characteristic of the synapses between the movement detectors and the FD1 cell should lead to a dramatic increase in the response amplitude of the FDl cell after the VCH cell is ablated. This, however, was not observed (Fig. 7) (Warzecha et al., 1993).

As an alternative mechanism it was therefore proposed that pattern size and velocity are already differentiated in the inhibitory signal mediated by the VCH cell (Borst and Egelhaaf, 1993b). This can be accomplished formally by assuming that the inhibitory signal increases linearly with pattern velocity but overproportionally with pattern size:

$$
R_{\mathrm{vCH}}=\left(N^{n} \cdot x\right) \text {, }
$$

with $n>1$. If the $\mathrm{VCH}$ cell is again assumed to inhibit the movement detectors presynaptically to the FDl cell by shunting inhibition, the response of the model FD1 cell is given by

$$
R_{\text {rDI }}=N \cdot\left[x /\left(\beta+N^{n} \cdot x\right)\right],
$$

which has been shown by computer simulations to match the corresponding experimental data quite well (Borst and Egelhaaf, 1993b). It should be noted that such a mechanism, though sim- 
ple in principle, is not easily implemented by the neuronal hardware. However, recent experimental results indicate how this may be possible (Egelhaaf et al., 1993). (1) The main dendritic arborization of the VCH cell in the third visual neuropil is likely to be both postsynaptic to the input from movement detectors and presynaptic to the FD1 cell or its movement detector input (Fig. $1 H)$. Hence, the inhibitory action of the VCH cell onto the FD1 cell is not localized but distributed over the entire dendritic tree. As a consequence of such a dendrodendritic connection, increases in pattern size or pattern velocity may lead to different activity distributions in the VCH cell, and thus to spatially differentiated inhibitory input to the FD1 cell. (2) Optical imaging reveals that the calcium concentration in the joint post- and presynaptic arborization of the $\mathrm{VCH}$ cell increases overproportionally with the size of the motion stimulus (Egelhaaf et al., 1993). Since calcium is known to regulate transmitter release, this presynaptic calcium may well reflect the amplitude and distribution of the inhibitory signal the $\mathrm{VCH}$ cell exerts onto the FD 1 cell. If this conclusion is correct, the inhibitory signal indeed increases overproportionally with stimulus size. As a consequence, the FD1 cell is inhibited only weakly when there is a small object, but strongly during large-field motion.

\section{Conclusions}

As studies of the visual orientation behavior of the fly have demonstrated, there exist several useful levels of explanation of how the brain processes behaviorally relevant information. These range from the behavioral phenomenology of the whole fly to the biophysical properties of individual neurons and their synaptic interactions. The relation between the different levels of explanation is not straightforward. Models providing a phenomenological description of the behavioral performance do not necessarily have their direct counterpart at the neuronal level. For instance, the phenomenological decomposition of the responses of the fly to moving stimuli into a direction-sensitive compensatory optomotor response and a direction-insensitive object fixation response is primarily a formal one (see section 3) that is useful for describing the overall performance of the system. However, there is no exact one-to-one relationship between these formally derived response components and the control systems at the neuronal level. Of the two neural pathways mediating optomotor and object fixation responses, the former is not completely direction sensitive and the latter not completely direction insensitive. Instead, they have complex spatiotemporal characteristics and may deviate considerably from what may be considered optimal from a theoretical point of view.

Although it is often not possible immediately to link explanations at behavioral and neuronal levels, this does not necessarily imply that the two levels of explanation are completely independent, as has previously been proposed (Marr, 1982). There is evidence, at least for the fly, that the algorithms underlying a computational task are constrained not only by the task itself but also by the way the algorithms are implemented by the neuronal hardware. Two examples may suffice to illustrate this point. (1) As was explained in sections 5.1. and 5.2., the tangential cells receive their main input from an array of local movement detectors, consisting of two subunits with opposite polarity. The two subunits terminate on the tangential cells with excitatory and inhibitory synapses. This opponent input enhances the direction selectivity of the tangential cells. Theoretical considerations have shown that this increase in di- rection selectivity is optimal, if the combination of the excitatory and inhibitory synapses corresponds to a mathematical subtraction (Egelhaaf et al., 1989; Borst and Egelhaaf, 1990). In fact, a subtraction stage is one of the main processing steps in the formal movement detector model proposed to underlie visual motion detection in biological systems (Reichardt, 1961; Borst and Egelhaaf, 1989). However, a mathematical subtraction is not a trivial consequence of combining an excitatory and an inhibitory synaptic input. A requirement for a perfect subtraction is that the ionic driving forces of both synaptic input channels must be exactly equal with only their polarity being inverted. This, however, is usually not given in most nerve cells, since the resting membrane potential of nerve cells is usually much closer to the reversal potential of the IPSPs than to the EPSPs. In the fly tangential cells, the resting potential is less negative, with the consequence that the driving forces of the cxcitatory and inhibitory input channels are at least similar. Hence, the interaction of the output of the two movement detector subunits comes close to a mathematical subtraction. Nevertheless, there are still deviations from a mathematical subtraction, with the consequence that the tangential cells are not completely direction sensitive. Their response still contains a small direction-insensitive component, because they respond to some extent also to temporal changes in overall brightness of the image (Egelhaaf et al., 1989). (2) A control system mediating the detection and fixation of small objects may be regarded as optimal, if the sensory filters in its input lines are exclusively sensitive to objects of the appropriate size independently of other stimulus parameters. This, however, is difficult to achieve by mechanisms that can be readily implemented by neural interactions, because the responses of all visual interneurons that are known in insects and vertebrates are not influenced by a single stimulus parameter alone. We have seen in section 5.4. the computational strategies by which the fly at least approximates this ideal performance. Yet, the FD cells are not perfectly tuned to small moving objects and respond to some extent also to large stimulus patterns.

Nevertheless, it appears that despite all these imperfections of the control systems imposed by the limitations of the neural hardware, the fly is able to perform its complex flight maneuvers (Land and Collett, 1974; Bülthoff et al., 1980; Wehrhahn et al., 1982; Wagner, 1986a,b). The main reason for this may be that free flight occurs under closed loop conditions, where deviations from the optimal performance can be immediately corrected by appropriate steering maneuvers. For instance, if a fly detects an object and tries to fixate it in its frontal visual field by a turning response, it may overshoot the target. This leads to an error signal in the object fixation pathway that induces another corrective turn toward the object.

Although optomotor and object fixation responses are not restricted to the fly and have to be performed by many fastmoving animals, it is not yet known whether the mechanisms used by the fly to accomplish these tasks are widespread among animals. Nevertheless, it is clear that optomotor and object fixation responses are mediated by separate pathways in a variety of species and that in the visual input lines these pathways incorporate filters that are tuned to the motion of either coherent large fields or small objects relative to their background. Such pathways operate in other insects (Collett, 1971; Palka, 1972; Collett and King, 1975; Olberg, 1981; DeVoe et al., 1982) as well as in a variety of vertebrate species (Simpson, 1984; Allman et al., 1985; Tanaka et al., 1986; Frost et al., 1990) including 
man (Baker and Braddick, 1982; van Doorn and Koenderink, 1982a,b; Regan, 1986). As for pathways tuned to the motion of small objects, neurons with stimulus-response properties similar to those of the FD cells have been found in the middle temporal region (area MT) of monkey cortex (Allman et al., 1985; Tanaka et al., 1986). Moreover, lesions in MT lead to deficits in ocular tracking of small objects and, hence it has been proposed that these cells participate in the control of cye movements (Newsome et al., 1985). As for pathways tuned to coherent motion of large fields, physiological and anatomical studies in a variety of vertebrate species have pointed to the role of the "accessory optic system" (AOT) for processing such stimuli to drive compensatory eye and head responses (Simpson, 1984). These pathways might thus be functionally analogous to the fly's HS cells. Although these analogies indicate common computational strategies throughout the animal kingdom, it is only in the fly that computations responsible for the specific selectivities of visual pathways have been accounted for in terms of biophysical properties of nerve cells and synaptic interactions.

\section{References}

Allman J, Miezin F, McGuinness E (1985) Direction- and velocityspecific responses from beyond the classical receptive field in the middle temporal visual area (MT). Perception 14:105-126.

Baker CL, Braddick OJ (1982) The basis of area and dot number effects in random dot motion perception. Vision Res 22:1253-1259.

Bausenwein B, Wolf R, Heisenberg M (1986) Genetic dissection of optomotor behavior in Drosophila melanogaster. Studies on wildtype and the mutant optomotor-blind H31. J Neurogenet 3:87-109.

Borst A (1990) How do flies land? From behavior to neuronal circuits. Bioscience 40:292-299.

Borst A (1991) Fly visual interneurons responsive to image expansion. Zool Jb Physiol 95:305-313.

Borst A, Egelhaaf M (1989) Principles of visual motion detection. Trends Neurosci 12:297-306.

Borst A, Egelhaaf M (1990) Direction selectivity of fly motion-sensitive neurons is computed in a two-stage process. Proc Natl Acad Sci USA 87:9363-9367.

Borst A, Egelhaaf M (1992) In vivo imaging of calcium accumulation in fly interneurons as elicited by visual motion stimulation. Proc Natl Acad Sci USA 89:4139-4143.

Borst A, Egelhaaf M (1993a) Detecting visual motion: theory and models. In: Visual motion and its role in the stabilization of gaze (Miles FA, Wallman J, eds), pp 3-27. Amsterdam: Elsevier.

Borst A, Egelhaaf M (1993b) Processing of synaptic signals in fly visual interneurons selectively responsive to small moving objects. In: Brain theory-spatio-temporal aspects of brain function (Acrtsen $A$, von Seelen W, eds), pp 47-66. Amsterdam: Elsevier.

Bülthoff H (1981) Figure-ground discrimination in the visual system of Drosophila melanogaster. Biol Cybern 41:139-145.

Bülthoff H, Poggio T, Wehrhahn C (1980) 3-D analysis of the flight trajectories of flies (Drosophila melanogaster). Z Naturforsch $35 \mathrm{c}$ : 811-815.

Churchland PS, Sejnowski TJ (1992) The computational brain. Cambridge, MA: MIT Press.

Collett TS (1971) Visual neurones for tracking moving targets. Nature 232:127-130.

Collett TS, King AJ (1975) Vision during flight. In: The compound eye and vișion of insects (Horridge GA, ed), pp 437-466. Oxford: Clarendon.

DeVoe RD, Kaiser W, Ohm J, Stone LS (1982) Horizontal movement detectors of honeybees: directionally-selective visual neurons in the lobula plate and brain. J Comp Physiol 147:155-170.

Egelhaaf $M$ (1985a) On the neuronal basis of figure-ground discrimination by relative motion in the visual system of the fly. I. Behavioural constraints imposed on the neuronal network and the role of the optomotor system. Biol Cybern 52:123-140.

Egelhaaf M (1985b) On the neuronal basis of figure-ground discrimination by relative motion in the visual system of the fly. II. Figuredetection cells, a new class of visual interneurones. Biol Cybern 52: 195-209.
Egelhaaf M (1985c) On the neuronal basis of figure-ground discrimination by relative motion in the visual system of the fly. III. Possible input circuitries and behavioural significance of the FD-cells. Biol Cybcrn 52:267-280.

Egelhaaf M (1987) Dynamic properties of two control systems underlying visually guided turning in house-flies. J Comp Physiol [A] 161:777-783.

Egelhaaf M (1989) Visual afferences to fight steering muscles controlling optomotor response of the fly. J Comp Physiol [A] 165:719730.

Egelhaaf M (1990) How do fly FD-cells acquire their sensitivity to small-field motion. Naturwissenschaften 77:182-185.

Egelhaaf M, Borst A (1992) Are there separate ON and OFF channels in fly motion vision? Vis Neurosci $8: 151-164$.

Egelhaaf M, Borst A (1993a) Movement detection in arthropods. In: Motion and its role in the stabilization of gaze (Wallman J, Miles FA, eds), pp 53-77. Amsterdam: Elsevier.

Egelhaaf M, Borst A (1993b) Motion computation and visual orientation in flies. Comp Biochem Physiol 104A:659-673.

Egelhaaf M, Hausen K, Reichardt W, Wehrhahn C (1988) Visual course control in flies relies on neuronal computation of object and background motion. Trends Neurosci 11:351-358.

Egelhaaf M, Borst A, Reichardt W (1989) Computational structure of a biological motion detection system as revealed by local detector analysis in the fly's nervous system. J Opt Soc Am [A] 6:1070-1087.

Egelhaaf M, Borst A, Pilz B (1990) The role of GABA in detecting visual motion. Brain Res 509:156-160.

Egelhaaf M, Borst A, Warzecha A-K, Flecks S, Wildemann A (1993) Neural circuit tuning fly visual neurons to motion of small objects. II. Input organization of inhibitory circuit elements by electrophysiological and optical recording techniques. J Neurophysiol 369:340351.

Fermi G, Reichardt W (1963) Optomotorische Reaktionen der Fliege Musca domestica. Abhängigkeit der Reaktion von der Wellenlänge, der Geschwindigkeit, dem Kontrast und der mittleren Leuchtdichte bewegter periodischer Muster. Kybernetik 2:15-28.

Frost BJ, Wylie DR, Wang Y-C (1990) The processing of object and self-motion in the tectofugal and accessory optic pathways of birds. Vision Res 30:1677-1688.

Geiger G, Nässel DR (1981) Visual orientation behaviour of flies after selective laser beam ablation of interneurones. Nature 293:398-399.

Geiger G, Nässel DR (1982) Visual processing of moving single objects and wide-field patterns in flies: behavioural analysis after laser-surgical removal of interneurons. Biol Cybern 44:141-149.

Götz KG (1964) Optomotorische Untersuchung des visuellen Systems ciniger Augenmutanten der Fruchtfliege Drosophila. Kybernetik 2:7792.

Götz KG (1983) Genetischer Abbau der visuellen Orientierung bei Drosophila. Verh Dtsch Zool Ges 76:83-99.

Haag J, Egelhaaf M, Borst A (1992) Dendritic integration of visual motion information in the fly. Neurosci Lett 140:173-176.

Hardie RC (1989) Neurotransmitters in compound eyes. In: Facets of vision (Stavenga DG, Hardie RC, eds), pp 235-256. Heidelberg: Springer.

Hassenstein B (1958) Über die Wahrnehmung der Bewegung von Figuren und unregelmäßigen Helligkeitsmustern. Z Vergl Physiol 40: 556-592.

Hausen K (1981) Monocular and binocular computation of motion in the lobula plate of the fly. Verh Dtsch Zool Ges 74:49-70.

Hausen K (1982a) Motion sensitive interneurons in the optomotor system of the fly. I. The horizontal cells: structure and signals. Biol Cybern 45:143-156.

Hausen K (1982b) Motion sensitive interneurons in the optomotor system of the fly. II. The horizontal cells: receptive field organization and response characteristics. Biol Cybern 46:67-79.

Hausen K (1984) The lobula-complex of the fly: structure, function and significance in visual behaviour. In: Photoreception and vision in invertebrates (Ali MA, ed), pp 523-559. New York: Plenum.

Hausen K, Egelhaaf M (1989) Neural mechanisms of visual course control in insects. In: Facets of vision (Stavenga D, Hardic R, eds), pp 391-424. Berlin: Springer.

Hausen K, Wehrhahn C (1990) Neural circuits mediating visual flight in flies. II. Separation of two control systems by microsurgical brain lesions. J Neurosci 10:351-360.

Heisenberg M, Wolf R (1984) Vision in Drosophila. Berlin: Springer. 
Heisenberg M, Wonneberger R, Wolf R (1978) Optomotor-blind-a Drosophila mutant of the lobula plate giant neurons. J Comp Physiol 124:287-296.

Koenderink JJ (1986) Optic flow. Vision Res 26:161-180.

Land MF, Collett TS (1974) Chasing behaviour of houseflies (Fannia canicularis). A description and analysis. J Comp Physiol 89:331-357.

Marr D (1982) Vision. San Francisco: Freeman.

Marr D, Poggio T (1977) From understanding computation to understanding neural circuitry. Neurosci Res Bull 15:470-488.

McCann GD (1973) The fundamental mechanism of motion detection in the insect visual system. Kybernetik 12:64-73.

Newsome WT, Wurtz RH, Dürsteler MR, Mikami A (1985) Deficits in visual motion processing following ibotenic acid lesions of the middle temporal visual area of the macaque monkey. J Neurosci 5:825-840.

Olberg RM (1981) Object- and self-movement detectors in the ventral nerve cord of the dragonfly. J Comp Physiol 141:327-334

Palka J (1972) Moving movement detectors. Am Zool 12:497-505.

Poggio T, Reichardt W (1976) Visual control of orientation behavior in the fly. Pt II. Towards the underlying neural interactions. Q Rev Biophys 9:377-438.

Poggio T, Reichardt W, Hausen K (1981) A neuronal circuitry for relative movement discrimination by the visual system of the fly. Naturwissenschaften 68:443-446.

Regan D (1986) Visual processing of four kinds of relative motion. Vision Res 26:127-145.

Reichardt W (1961) Autocorrelation, a principle for the evaluation of sensory information by the central nervous system. In: Sensory communication (Rosenblith WA, ed), pp 303-317. New York: MIT PressWiley.

Reichardt W (1973) Musterinduzierte Flugorientierung. VerhaltensVersuche an der Fliege Musca domestica. Naturwissenschaften 60 : 122-138.

Reichardt W (1979) Functional characterization of neural interactions through an analysis of behaviour. In: The neurosciences, Fourth study program (Schmitt FO, ed), pp 81-104. Cambridge, MA: MIT Press.

Reichardt W, Poggio $T$ (1975) A theory of the pattern induced flight orientation of the fly Musca domestica II. Biol Cybern 18:69-80.

Reichardt W, Poggio T (1976) Visual control of orientation behaviour in the fly. Pt I. A quantitative analysis. Q Rev Biophys 9:311-375.

Reichardt W, Poggio T (1979) Figure-ground discrimination by relative movement in the visual system of the fly. $\mathrm{Pt} \mathrm{I}$ : Experimental results. Biol Cybern 35:81-100.

Reichardt W, Poggio T, Hausen K (1983) Figure-ground discrimination by relative movement in the visual system of the fly. $\mathrm{Pt}$ II: Towards the neural circuitry. Biol Cybern [Suppl] 46:1-30.

Reichardt W, Egelhaaf M, Guo A (1989) Processing of figure and background motion in the visual system of the fly. Biol Cybern 61: 327-345.

Schmid A (1993) Neurotransmitters involved in movement detection in the visual system of an arthropod. Naturwissenschaften 79:564 567.

Schmid A, Bülthoff H (1988) Using neuropharmacology to distinguish between excitatory and inhibitory movement detection mechanisms in the fly Calliphora erythrocephala. Biol Cybern 59:71-80.

Schuling FH, Mastebroek HAK, Bult R, Lenting BPM (1989) Properties of elementary movement detectors in the fly Calliphora erythrocephala. J Comp Physiol [A] 165:71-80.

Sejnowski TJ, Koch C, Churchland P (1988) Computational neuroscience. Science 241:1299-1306.

Sekuler R, Anstis S, Braddick OJ, Brandt T, Movshon JA, Orban GA (1990) The perception of motion. In: Visual perception (Spillman $L$, Werner JS, eds). New York: Academic.

Simpson JI (1984) The accessory optic system. Annu Rev Neurosci $7: 13-41$

Strausfeld NJ (1976) Atlas of an insect brain. Berlin: Springer.

Strausfeld NJ (1989) Beneath the compound eye: neuroanatomical analysis and physiological correlates in the study of insect vision. In: Facets of vision (Stavenga DG, Hardie RC, eds), pp 317-359. Berlin: Springer.

Tanaka K, Hikosaka K, Saito H, Yukie M, Fukada Y, Iwai E (1986) Analysis of local and wide-field movements in the superior temporal visual areas of the macaque monkey. J Neurosci 6:134-144.

van Doorn AJ, Koenderink JJ (1982a) Temporal properties of the visual detectability of moving spatial white noise. Exp Brain Res 45: $179-188$

van Doorn AJ, Koenderink JJ (1982b) Spatial properties of the visual detectability of moving spatial white noise. Exp Brain Res 45:189195.

Virsik R, Reichardt W (1976) Detection and tracking of moving objects by the fly Musca domestica. Biol Cybern 23:83-98.

Wagner H (1986a) Flight performance and visual control of the flight of the free-flying housefly (Musca domestica). II. Pursuit of targets. Philos Trans R Soc Lond [Biol] 312:553-579.

Wagner $\mathrm{H}$ (1986b) Flight performance and visual control of tlight of the free-flying housefly ( $M u s c a$ domestica). III. Interactions between angular movement induced by wide- and smallfield stimuli. Philos Trans R Soc Lond [Biol] 312:581-595.

Warzecha A-K, Borst A, Egelhaaf M (1992) Photo-ablation of single neurons in the fly visual system reveals neural circuit for the detection of small moving objects. Neurosci Lett 141:119-122.

Warzecha A-K, Egelhaaf M, Borst A (1993) Neural circuit tuning fly visual neurons to motion of small objects. I. Dissection of the circuit by pharmacological and photoinactivation techniques. J Neurophysiol 69:329-339.

Wehrhahn C (1985) Visual guidance of flies during flight. In: Comprehensive insect physiology, biochemistry and pharmacology (Kerkut GA, Gilbert LI, eds), pp 673-684. Frankfurt: Pergamon.

Wehrhahn C, Hausen K (1980) How is tracking and fixation accomplished in the nervous system of the fly? A behavioural analysis based on short time stimulation. Biol Cybern 38:179-186.

Wehrhahn C, Poggio T, Bülthoff H (1982) Tracking and chasing in houseflies (Musca). Biol Cybern 45:123-130.

Zeil J (1986) The territorial flight of male houseflies (Fannia canicularis). Behav Ecol Sociobiol 19:213-219. 